\title{
KOMODIFIKASI KATA HALAL PADA IKLAN HIJAB ZOYA VERSI CANTIK NYAMAN HALAL
}

\author{
Rizka Trisna Arianti ${ }^{1}$, Hadi Purnama ${ }^{2}$ \\ Fakultas Komunikasi dan Bisnis, Program Studi Ilmu Komunikasi, Universitas Telkom, Bandung \\ Naskah diterima tanggal 27 Agustus, direvisi tanggal 29 Agustus, disetujui tanggal 3 September
}

\begin{abstract}
Abstrak. Indonesia, sebagai negara dengan mayoritas penduduk muslim, memberikan sertifikat halal untuk berbagai macam jenis produk yang diperjualbelikan sebagai jaminan agar masyarakat bisa menjalankan agamanya dengan tenang. Namun media cenderung memanfaatkan sertifikat halal tersebut untuk mengkomodifikasikan nilai agama. Fenomena komodifikasi ini muncul dalam iklan hijab Zoya versi "Cantik Nyaman Halal" melalui penggunaan kata 'halal'. Penelitian ini dilakukan untuk mengetahui ragam wacana yang digunakan untuk mengkomodifikasikan kata halal pada iklan; bagaimana komodifikasi kata halal ditampilkan pada struktur iklan; bagaimana gaya penyampaian iklan yang digunakan untuk mengkomodifikasikan kata halal pada iklan; dan jenis dan tingkat modalitas yang digunakan untuk mengkomodifikasikan kata halal pada iklan. Metode penelitian yang digunakan adalah kualitatif dengan paradigma kritis. Analisis data yang digunakan adalah semiotika sosial Theo Van Leeuwen dengan menggunakan empat dimensi analisis yaitu discourse, genre, style, dan modality. Hasil penelitian memperlihatkan beberapa kesimpulan: iklan Zoya mengkomodifikasikan nilai agama melalui wacana hijab halal sebagai karakteristik utama, iklan Zoya mengkomodifikasikan nilai agama yaitu kata halal bagian badan iklan dan penutup, iklan Zoya merepresentasikan gaya hidup religius yang modern dengan penyampaian gaya iklan yang santai dan realistis, serta iklan Zoya mempunyai jenis modalitas epistemik dengan tingkatan medium dan jenis deontik dengan tingkatan tinggi.
\end{abstract}

\section{Kata kunci: Komodifikasi, Iklan, Halal, Semotika.}

\begin{abstract}
Indonesia, as a muslim-majority country, gives halal certificate for many kinds of products who are sold so that people can practice their religion with ease. However, media tends to take advantage on this halal certification to commodify the value of religion. This phenomenon shows up in hijab Zoya's commercial 'Cantik Nyaman Halal' version which commodified religion value such as halal word. This research objective is to perceive the commercial's discourse to commodified halal word; how does the commodification of halal word displayed on the commercial's structure; how is the style of the commercial used to commodify halal word; and to perceive the types and levels of modalistiy that are used to commodify halal word. Method used in this research is qualitative with critical paradigm. Data analysis used in this research is social semiotics by Theo Van Leeuwen which used four analysis dimensions, such as discourse, genre, style, and modality. The result of this research shows conclusion such as: Zoya's commercial commodified religion value through the discourse about halal hijab as main and important characteristic, Zoya's commercial commodified halal word in body advertisement and closing, Zoya's commercial represented modern and religious lifestyle with informal and realistic commercial's style, and Zoya's commercial has epistemic modality in medium level and deontic modality in high level.
\end{abstract}

Keywords: Commodification, Commercial, Halal, Semiotics. 


\section{PENDAHULUAN}

Iklan dapat didefinisikan sebagai pesan yang menawarkan suatu produk yang ditunjukan kepada masyarakat lewat suatu media (Kertamukti, 2015: 62). Banyak ahli yang mengidentifikasikan iklan sebagai bagian penting dalam proses pembentukan gaya hidup. Iklan televisi dikemas sedemikian menarik, menyapa setiap detik, menyuntikkan ideologi atau kepentingan lain yang dihendaki perusahaan pembuat iklan. Masyarakat kerap tidak menyadari bahwa ada suatu nilai, budaya, atau agama yang dikomodifikasi dalam bentuk iklan. Vincent Mosco mendefinisikan komodifikasi sebagai "proses mengubah barang dan jasa, termasuk komunikasi, yang dinilai karena kegunaanya, menjadi komoditas yang dinilai karena apa yang akan mereka berikan di pasar." (Ibrahim dan Akhmad, 2014: 17).

Sebagai negara dengan mayoritas penduduk bergama Islam, agama kerap terlibat di media. Namun yang tidak disadari, banyak penggunaan nilai agama yang dibalut kapitalisme dan dijadikan alat komoditas. Fenomena dari komersialisasi agama yang sering muncul akhir-akhir ini adalah fenomena produk yang diberikan label halal di Indonesia. Perusahaan berbondongbondong mempromosikan produk mereka sebagai produk yang sudah mendapat seritifikasi halal dan di asosiasikan dengan nilai-nilai agama. Hal ini terjadi karena nilai pasar produk halal dan kebutuhan masyarakat atas produk halal semakin meningkat. Di Indonesia, seluruh produk yang dipasarkan bisa mendapatkan sertifikasi halal dari Lembaga Pengkajian Pangan Obat obatan dan Kosmetika Majelis Utama Indonesia (LPPOM MUI). Sertifikat ini diberikan pada produk yang sudah dinyatakan menurut syariat Islam.

Selain produk halal, Indonesia menaruh perhatian yang cukup besar pada industri fashion muslim. Kian hari semakin marak merek busana muslim yang muncul di pasaran. Zoya adalah satu merek hijab dan busana muslim di Indonesia yang berdiri sejak tahun 2005. Zoya fokus pada industri fashion muslim yang modis dengan harga terjangkau untuk costumer kelas menengah. Tahun 2016 silam, Zoya mengumumkan bahwa produk mereka telah mendapatkan sertifikasi halal dari LPPOM MUI. Zoya juga mengeluarkan iklan komersial televisi yang menegaskan bahwa produk Zoya halal digunakan. Hal ini menciptakan kontroversi yang mempertanyakan aspek halal dari produk gunaan. Zoya juga telah memperoleh penghargaan sebagai merek hijab terbaik sejak 2015 dalam ajang Best Brand Award dan Top Brand Indonesia. Dapat dikatakan bahwa Zoya mempunyai peran yang besar untuk menciptakan tren dan lifestyle bagi pemakai hijab di Indonesia. Peneliti beranggapan bahwa terlepas dari 
kebutuhan muslim untuk mencari produk yang halal, tidak seharusnya nilai halal tersebut dikomodifikasikan dalam sebuah iklan yang semata-mata hanya mencari keuntungan semata.

Peneliti tertarik meneliti penggunaan nilai halal yang ditonjolkan pada iklan Zoya versi Cantik Nyaman Halal tersebut menggunakan metode analisis semiotika sosial.

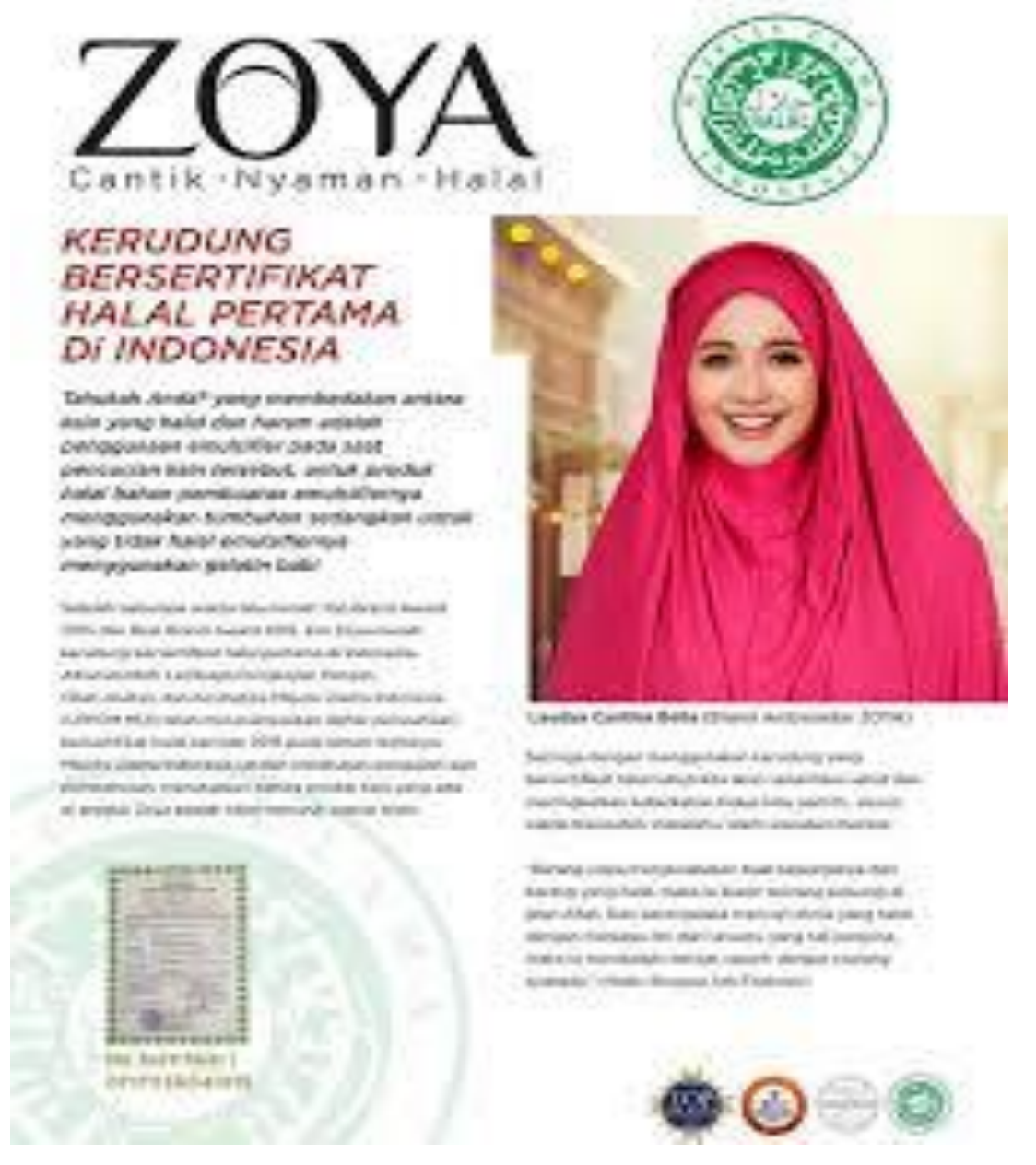

Sumber : https://www.zoya.co.id/ Gambar 1. Zoya (Cantik-Nyaman-Halal)

Semiotika sosial menurut Theo Van Leeuwen adalah cara untuk mempelajari suatu sumber daya semiotika yang digunakan untuk tujuan-tujuan komunikasi, bahwa komunikasi kemudian dianggap sebagai sebuah proses memanipulasi objek, dan tanda dalam logika ini adalah sebuah hasil manipulasi dari objek-objek tertentu dalam kehidupan berupa simbol-simbol dengan tujuan untuk berkomunikasi. Sumber-sumber semiotika dalam semiotika sosial tidak hanya diteliti artinya, namun juga bagaimana sumber tersebut digunakan dalam konteks (Leeuwen, 2005: 5). Berdasarkan latar belakang yang telah dipaparkan, maka identifikasi masalah dalam penelitian ini adalah bagaimana bentuk komodifikasi pada kata halal dalam iklan 


\section{METODE PENELITIAN}

Penelitian ini menggunakan metode penelitian kualitatif dengan paradigma kritis. Dalam pandangan teori kritis, para tokohnya berupaya mengungkap dominasi, eksploitasi, dan penindasan guna membantu individu atau kelompok masyarakat dalam memahami akar dominasi, eksploitasi, dan penindasan yang mereka alami. Teknik analisis data yang digunakan adalah dengan menggunakan analisis semiotika sosial Theo Van Leeuwen. Van Leeuwen dalam teori semiotikanya mengatakan bahwa semiotika mempelajari suatu sumber daya semiotika yang digunakan untuk tujuan-tujuan komunikasi, bahwa komunikasi kemudian dianggap sebagai sebuah proses memanipulasi objek (van Leeuwen 2005 : 5). Dalam analisisnya, tanda atau konfigurasi tanda bisa dibedah dengan melihat dimensi-dimensi semiotik yang oleh Theo Van Leeuween dibedakan menjadi 4 dimensi: discourse, genre, style dan modality.

\section{HASIL PENELITIAN DAN PEMBAHASAN}

Istilah iklan atau advertising berasal dari kata Latin abad pertengahan yaitu "advertere" yang berarti "mengarahkan perhatian kepada" (Danesi, 2004: 362). Istilah ini menggambarkan aktivitas yang bermaksud menyebarkan sebuah pesan untuk publik. Danesi (2004: 362) menjelaskan bahwa di abad keduapuluh periklanan berevolusi menjadi sebuah strategi sosial persuasif yang dimaksudkan untuk memengaruhi cara orang memandang pembelian dan konsumsi barang. Hingga hari ini, subteks periklanan bertujuan untuk mengangkat dan memancangkan nilai-nilai kenikmatan hidup.

Dalam teori ekonomi politik, terdapat dua nilai produk, yang pertama adalah "nilai guna" (use value) yaitu nilai produk yang muncul dari pemuasan keinginan dan kebutuhan manusia, sedangkan yang kedua adalah "nilai tukar" (exchange value) yang dinilai berdasarkan atas apa yang ia bisa berikan dalam pertukaran. Proses perubahan nilai guna menjadi nilai tukar disebut dengan komodifikasi (Ibrahim dan Akhmad, 2014: 17). Vincent Mosco (dalam Ibrahim dan Akhmad, 2014: 20-21) menjabarkan tentang tiga tipe komodifikasi dalam komunikasi, yaitu: Komodifikasi Isi, Komodifikasi Khalayak, dan Komodifikasi Tenaga Kerja. Namun seiring dengan perkembangan ilmu pengetahuan, Ibrahim dan Akhmad (2014: 21-24) menambahkan dua tipe tambahan komodifikasi, yaitu komodifikasi kanak-kanak dan komodifikasi nilai. Iklan mempunyai peran penting dalam mengemas budaya dan nilai kehidupan, terkadang hal ini berujung pada komodifikasi nilai.

Halal adalah perkara yang diperbolehkan dan dilepaskan dari ikatan larangan serta diizinkan syariat untuk dilakukan. Sedangkan yang dimaksud dengan haram adalah perkara yang 
dilarang syariat untuk dilakukan dengan larangan yang bersifat tegas. Jika melanggar, maka akan mendapatkan hukuman dari Allah di akhirat (al-Qaradhawi, 2017: 21). Larangan haram dalam agama Islam meliputi berbagai aspek dalam kehidupan, termasuk makanan dan minuman, cara mendapatkan uang, berdagang, hiburan, hubungan antar individu, dan lain sebagainya.

Di Indonesia terdapat Undang-Undang Jaminan Produk Halal nomor 33 Tahun 2014. Dalam pasal 4 disebutkan bahwa seluruh produk yang masuk, beredar, dan diperdagangkan di wilayah Indonesia wajib bersertifikat halal. Sertifikat halal dikeluarkan melalui Lembaga Pengkajian Pangan, Obat-obatan dan Kosmetika Majelis Ulama Indonesia atau yang disingkat LPPOM MUI.

Semiotika sosial pertama kali dikemukakan oleh M.A.K Halliday yang berpendapat bahwa grammar dalam sebuah bahasa bukanlah kode atau seperangkat aturan untuk memproduksi kalimat yang benar, melainkan sebuah sumber untuk menciptakan makna (Leeuwen, 2005: 3). Van Leeuwen dalam teori semiotikanya mengatakan bahwa semiotika mempelajari suatu sumber daya semiotika yang digunakan untuk tujuan-tujuan komunikasi, bahwa komunikasi kemudian dianggap sebagai sebuah proses memanipulasi objek, dan tanda dalam logika ini adalah sebuah hasil manipulasi dari objek-objek tertentu dalam kehidupan berupa simbol-simbol dengan tujuan untuk berkomunikasi.

Van Leeuwen menggunakan istilah "sumber-sumber semiotik" untuk mengganti istilah "tanda". Menurutnya walaupun "tanda" merupakan sesuatu konsep yang fundamental dalam semiotik, namun "tanda" dipandang sebagai sesuatu yang tidak tetap. "Sumber-sumber semiotik" juga digunakan untuk memproduksi artefak dan peristiwa komunikasi.

Terdapat empat dimensi semiotik untuk membedah teks dalam analisis semiotika sosial, yaitu discourse, genre, style, dan modality. Discourse atau wacana merupakan kunci dari mempelajari bagaimana sumber-sumber semiotika digunakan untuk mengkonstruksi representasi dari teks tersebut. Dalam sebuah wacana, terdapat elemen yang digunakan untuk menganalisa, yaitu: actions, manner, actors, presentation, resources, times, spaces, exclusion, rearrangement, addition, dan substitution, Van Leeuwen menggunakan genre untuk melakukan pendekatan "bagaimana" dari sebuah bentuk komunikasi dalam semiotika sosial.

Genre sendiri secara umum dapat diartikan sebagai 'tipe teks'. Teks mempunyai karakteristik yang dapat dikategorikan dalam berbagai tipe. Genre juga bisa dilihat dari struktur teks. Style dapat didefinisikan sebagai gaya komunikasi dan identitas dari teks. Van Leeuwen menjabarkan tiga pendekatan style yaitu individual style, social style, dan lifestyle. modalitas artinya adalah makna kemungkinan, keharusan, kenyataan, dan sebagainya yang dinyatakan dalam kalimat. Modalitas linguistik ditentukan bukan dari benar atau salah, melainkan tingkatan 
tinggi, sedang, atau rendah. Tingkatan modalitas ini bisa dilihat berdasarkan ekspresi dan penggunaan kata.

Setelah menganalisa iklan hijab Zoya versi Cantik Nyaman Halal yang berdurasi 30 detik ini, peneliti akan membahas hasil penelitian di bawah ini:

Sertifikat Halal 
Body ad dan Closing kata 'halal'

mereka, padahal belum tentu. Tindakan yang dilakukan Zoya mungkin dapat dibalut dengan alasan dakwah ataupun edukasi, namun pada akhirnya apa yang diiklankan ke masyarakat membawa umpan balik bagi Zoya, yaitu keuntungan yang berlipat ganda.

Iklan hijab Zoya versi Cantik Nyaman Halal mengkomodifikasikan nilai agama yaitu kata halal pada bagian body ad atau badan iklan dan closing atau penutup. Dalam body ad atau badan iklan hijab Zoya versi Cantik Nyaman Halal, Zoya menyampaikan informasi inti yaitu menawarkan apa yang dijual oleh Zoya pada konsumennya. Iklan ini lewat narasinya mempersuasi penonton untuk meyakini bahwa sebuah hijab haruslah cantik, nyaman, dan halal agar dapat melengkapi syariat Islam. Dalam bagian penutup iklan hijab Zoya versi Cantik Nyaman Halal, terdapat pengulangan informasi yang disingkat mengenai ketiga kriteria pemilihan hijab, yaitu cantik, nyaman, dan halal. Bagian penutup juga menegaskan informasi yang ingin disampaikan oleh iklan. Setelah itu Zoya juga menampilkan tagline mereka yaitu “Cantik, Nyaman, Halal.” untuk menutup keseluruhan iklan. Pengulangan dan penyimpulan informasi ini bertujuan agar penonton semakin mudah mengingat pesan yang disampaikan Zoya lewat iklannya

Iklan hijab Zoya versi Cantik Nyaman Halal merepresentasikan gaya hidup religius yang 
Gaya Hidup Religius

Fashion yang sesuai islam modern. Gaya hidup yang direpresentasikan kerap dekat dengan keseharian sehingga dengan mudah dapat disusupi nilai-nilai agama yang telah dikomodifikasikan. Dengan menggunakan simbol-simbol yang modern dan merepresentasikan nilai agama, Zoya lewat iklannya menciptakan ilusi bahwa dengan memilih hijab halal sebagai kriteria utama, maka khalayak seolah-olah telah mengadopsi gaya hidup religius dan membuat mereka merasa lega dengan pilihan produk mereka. Hijab halal disimbolkan sebagai kesempurnaan agama, sehingga khalayak merasa aman dan lega jika menggunakan hijab halal.

Iklan hijab Zoya versi Cantik Nyaman Halal mempunyai jenis modalitas epistemik dan deontik dengan tingkatan medium dan tinggi. Modalitas epistemik dengan tingkat medium berusaha meyakinkan penonton agar dapat menerima pesan yang ingin disampaikan oleh iklan, yaitu untuk memilih hijab yang cantik, nyaman, dan halal seperti yang ditawarkan oleh merek Zoya. Dalam iklan ini, modalitas deontik diungkapkan melalui kata halal yang berarti diizinkan dalam syariat Islam. Mengingat makna 'izin' dalam modalitas deontik memiliki tingkat yang tinggi, iklan hijab Zoya lewat narasinya berusaha memasukkan nilai agama untuk membuat sebuah urgensi dimana khalayak harus memiliki sebuah hijab yang memiliki sertifikat halal. 


\section{SIMPULAN}

Dari hasil penelitian, diperoleh beberapa kesimpulan yaitu: Iklan Zoya mengkomodifikasikan nilai agama melalui wacana tentang hijab halal sebagai karakteristik utama dan terpenting. Zoya memanfaatkan label halal yang berkaitan erat dengan unsur agama Islam sebagai materi promosi. Kata halal dan sertifikatnya dijadikan legitimasi bagi iklan untuk meyakinkan masyarakat bahwa produk yang dijual merupakan produk yang tepat untuk menjalankan perintah agama. Iklan Zoya mengkomodifikasikan nilai agama yaitu kata halal bagian badan iklan dan penutup untuk menyampaikan tujuan iklan yaitu mengedukasi umat muslim dalam menyempurnakan syariat agama dan juga untuk menciptakan gaya hidup islami dan menciptakan situasi dimana penonton tergerak untuk membeli hijab Zoya sebagai penyempurna syariat agama. Iklan Zoya merepresentasikan gaya hidup religius yang modern dengan penyampaian gaya iklan yang santai dan realistis dengan memunculkan simbol-simbol yang modern dan merepresentasikan Islam, Zoya menciptakan gaya hidup islami yang cenderung dikomodifikasikan untuk keuntungan Zoya semata. Iklan Zoya mempunyai jenis modalitas epistemik dengan tingkatan medium dan jenis deontik dengan tingkatan tinggi. Tujuannya untuk merepresentasikan umat muslim dan menciptakan urgensi agar penonton membeli hijab halal sebagai penyempurna syariat agama. 


\section{DAFTAR PUSTAKA}

\section{Buku:}

Achmad, Sani Supriyanto dan Vivin Maharani. (2003). Metodologi Penelitian Manajemen Sumber Daya Manusia. Malang: UIN-Maliki Press.

Danesi, Marcel. (2010). Pengantar Memahami SEMIOTIKA MEDIA. Yogyakarta: Jalasutra.

Fiske, John. (1990). Introduction To Communication. New York: Routledge.

Little John, Stephen W dan Karen A. Foss. (2011). Teori Komunikasi. Jakarta: Salemba Humanika.

Sobur, Alex. (2009). Semiotika Komunikasi. Bandung: PT. Remaja Rosdakarya.

\section{Artikel Internet:}

<http://m.imdb.com/Citizenfour >

$\langle$ http://www.LayarKaca21.com/Citizenfour $>$ 